\title{
Sporadic late-onset nemaline myopathy: clinico-pathological characteristics and review of 76 cases
}

Lukas J. Schnitzler ${ }^{1,2}$, Tobias Schreckenbach ${ }^{3}$, Aleksandra Nadaj-Pakleza ${ }^{4}$, Werner Stenzel ${ }^{5}$, Elisabeth J. Rushing ${ }^{6}$, Philip Van Damme ${ }^{7,8,9}$, Andreas Ferbert ${ }^{10}$, Susanne Petri ${ }^{11}$, Christian Hartmann ${ }^{12}$, Antje Bornemann ${ }^{13}$, Andreas Meisel ${ }^{14}$, Jens A. Petersen ${ }^{15}$, Thomas Tousseyn ${ }^{16}$, Dietmar R. Thal ${ }^{16,17}$, Jens Reimann ${ }^{18}$, Peter De Jonghe ${ }^{19,20}$, Jean-Jacques Martin ${ }^{21}$, Peter Y. Van den Bergh ${ }^{22}$, Jörg B. Schulz ${ }^{1,23}$, Joachim Weis ${ }^{2}$ and Kristl G. Claeys $1,2,7,24,25^{*}$

\begin{abstract}
Background: Sporadic late-onset nemaline myopathy (SLONM) is a rare, late-onset muscle disorder, characterized by the presence of nemaline rods in muscle fibers. Phenotypic characterization in a large cohort and a comprehensive overview of SLONM are lacking.

Methods: We studied the clinico-pathological features, treatment and outcome in a large cohort of 76 patients with SLONM, comprising 10 new patients and 66 cases derived from a literature meta-analysis (PubMed, 19662016), and compared these with 15 reported HIV-associated nemaline myopathy (HIV-NM) cases. In 6 SLONM patients, we performed a targeted next-generation sequencing (NGS) panel comprising 283 myopathy genes.

Results: SLONM patients had a mean age at onset of 52 years. The predominant phenotype consisted of weakness and atrophy of proximal upper limbs in $84 \%$, of proximal lower limbs in $80 \%$ and both in $67 \%$. Other common symptoms included axial weakness in 68\%, as well as dyspnea in 55\% and dysphagia in $47 \%$ of the patients. In $53 \%$ a monoclonal gammopathy of unknown significance (MGUS) was detected in serum. The mean percentage of muscle fibers containing rods was $28 \%$ (range 1-63\%). In 2 cases ultrastructural analysis was necessary to detect the rods. The most successful treatment in SLONM patients (all with MGUS) was autologous peripheral blood stem cell therapy. A targeted NGS gene panel in 6 SLONM patients (without MGUS) did not reveal causative pathogenic variants. In a comparison of SLONM patients with and without MGUS, the former comprised significantly more males, had more rapid disease progression, and more vacuolar changes in muscle fibers. Interestingly, the muscle biopsy of 2 SLONM patients with MGUS revealed intranuclear rods, whereas this feature was not seen in any of the biopsies from patients without paraproteinemia. Compared to the overall SLONM cohort, significantly more HIV-NM patients were male, with a lower age at onset (mean 34 years). In addition, immunosuppression was more frequently applied with more favorable outcome, and muscle biopsies revealed a significantly higher degree of inflammation and necrosis in this cohort. Similar to SLONM, MGUS was present in half of the HIV-NM patients.

(Continued on next page)
\end{abstract}

\footnotetext{
*Correspondence: kristl.claeys@uzleuven.be

'Department of Neurology, University Hospital RWTH Aachen, Aachen, Germany

${ }^{2}$ Institute of Neuropathology, University Hospital RWTH Aachen, Aachen,

Germany

Full list of author information is available at the end of the article
} 
(Continued from previous page)

Conclusions: SLONM presents a challenging, but important differential diagnosis to other neuromuscular diseases of adult onset. Investigations for MGUS and HIV should be performed, as they require distinct but often effective therapeutic approaches. Even though SLONM and HIV-NM show some differences, there exists a large clinicopathological overlap between the 2 entities.

Keywords: SLONM, Muscle biopsy, HIV-associated nemaline myopathy, HIV-NM, Monoclonal gammopathy, MGUS, NGS

\section{Background}

Sporadic late-onset nemaline myopathy (SLONM) is a rare, acquired, late-onset muscle disorder with subacute progression, characterized by proximal muscle weakness and atrophy, and the presence of nemaline rods in myofibers [1, 2]. Distal muscle weakness [3], dropped head $[4,5]$, respiratory failure $[6,7]$, or dysphagia $[8,9]$ have also been reported. SLONM can be associated with a monoclonal gammopathy of unknown significance (MGUS) that leads to an unfavorable outcome if untreated [10-13].

HIV-associated nemaline myopathy (HIV-NM) is another acquired, late-onset nemaline myopathy, distinguished by the presence of nemaline rods in muscle fibers in the setting of an HIV-infection [14-16]. An autoimmune mechanism for HIV-NM has been discussed [17, 18], however, it remains unclear whether HIV-NM and SLONM represent the same or distinct disease entities.

Histopathologically, nemaline rods can be identified on modified Gomori's trichrome staining (mGT) as subsarcolemmal or intermyofibrillar dark red clusters [19]. Using electron microscopy, the rods appear as electron dense bodies, sometimes showing continuity with the Zdiscs [20]. Rarely, nemaline bodies can occur inside myonuclei $[4,12,21,22]$. Rods also represent the histopathological hallmark of the inherited congenital nemaline myopathies, which are currently known to be caused by 11 different genes [23].

Several case reports and small series of patients with SLONM have been published so far, but a systematic overview of SLONM is lacking. Here, we studied the clinicopathological features as well as treatment and outcome in a large cohort of 76 patients with SLONM, comprising 10 new patients and 66 cases derived from a literature metaanalysis. In addition, we screened 283 myopathy genes using a targeted next-generation sequencing (NGS) panel in 6 SLONM patients and compared the phenotypic characteristics of the SLONM cohort $(n=76)$ with 16 HIVNM cases reported in the literature.

\section{Methods}

\section{SLONM patient selection}

Patients with histologically confirmed SLONM, who either presented at the neuromuscular outpatient clinic
(Department of Neurology) or had a muscle biopsy sent for (re-) evaluation to the Institute of Neuropathology at the University Hospital RWTH Aachen (Aachen, Germany), were included in our study. Patients with nemaline myopathy and a history or symptoms suggesting a congenital myopathy, such as positive family history for myopathy, the presence of delayed motor milestones, high-arched palate, scoliosis or muscle hypotonia were excluded. Patients with HIV infection were also excluded.

\section{Clinical and paraclinical examinations}

We performed a detailed neurological examination including muscle strength evaluation according to the criteria of the Medical Research Council (MRC) scale. Blood analyses were obtained including creatine kinase (CK) (normal in men $<190 \mathrm{U} / \mathrm{l}$, women $<170 \mathrm{U} / \mathrm{l}$ ), immune fixation and thyroid function as well as electromyography (EMG), nerve conduction studies (NCS), vital capacity measurement using spirometry, and echocardiography in all patients (Table 1, P1-10). The same examinations were performed in two patients (Table 1, P11-P12) who had been previously reported [9, 24], but who were re-evaluated in the current study and included for genetic analysis (see below).

\section{Histopathological examination}

Open muscle biopsies had been performed for diagnostic purposes prior to the study after obtaining the patients' written informed consent (Table 1, P1-10). Biopsies were processed for light microscopy (LM) and electron microscopy (EM) following standardized procedures [19]. Electron microscopic studies were performed in 49 published cases and all of our new patients but patient 4 , in whom only LM was available. All available LM sections and EM images were analyzed. Biopsies from two additional patients (Table 1, P11-P12) who had been previously reported $[9,24]$ were re-evaluated in the current study.

\section{Statistical analysis}

Statistical analysis was performed using Excel software (Version 16.0.7030.1021) with the Add-In Real Statistics Resource Pack (Release 4.3). We tested for normal distributions using the D'Agostino Pearson Omnibus and the 
Table 1 Clinical, paraclinical and muscle biopsy features in SLONM, and comparison with HIV-NM

\begin{tabular}{|c|c|c|c|c|c|c|c|c|c|c|c|c|c|c|c|c|}
\hline & \multicolumn{15}{|l|}{ SLONM } & \multirow{2}{*}{$\begin{array}{l}\text { HIV-NM } \\
\text { All HIV-NM } \\
\text { cases (15) }\end{array}$} \\
\hline & $\begin{array}{l}\text { All } \\
\text { SLONM } \\
\text { cases (76) }\end{array}$ & $\begin{array}{l}\text { With } \\
\text { gammopathy } \\
(27 / 76)\end{array}$ & $\begin{array}{l}\text { Without } \\
\text { gammopathy } \\
(24 / 76)\end{array}$ & $\begin{array}{l}\mathrm{P} \\
1\end{array}$ & $\begin{array}{l}P \\
2\end{array}$ & P 3 & P 4 & P 5 & P 6 & P 7 & P 8 & P 9 & P 10 & P 11 & $\begin{array}{l}P \\
12\end{array}$ & \\
\hline \multicolumn{17}{|l|}{ History: } \\
\hline Gender & $\underset{a}{35} \mathrm{~m} / 33 \mathrm{f}$ & $18 \mathrm{~m} / 9 \mathrm{f}$ & $7 \mathrm{~m} / 17 \mathrm{f}$ & m & $f$ & f & $f$ & $f$ & f & $\mathrm{m}$ & $f$ & $\mathrm{~m}$ & $f$ & $f$ & f & $13 \mathrm{~m} / 2 \mathrm{f}^{\mathrm{a}}$ \\
\hline $\begin{array}{l}\text { Age at onset } \\
\text { (mean/range) (y) }\end{array}$ & $\begin{array}{l}52 / 25-78 \\
a\end{array}$ & 49/25-78 & $53 / 27-78$ & 52 & 67 & 61 & 49 & 54 & 32 & 50 & 47 & 51 & 77 & 67 & 54 & $34 / 21-49^{a}$ \\
\hline $\begin{array}{l}\text { Age at examination } \\
\text { (mean/range) (y) }\end{array}$ & $56 / 27-79$ & $51 / 26-75$ & 58/34-79 & 55 & 72 & 67 & 49 & 79 & 34 & 51 & 48 & 52 & 79 & 79 & 60 & $34 / 21-49$ \\
\hline $\begin{array}{l}\text { Duration until diagnosis } \\
\text { (mean/range) (y) }\end{array}$ & $4 / 0-32$ & $2 / 0-7$ & $4 / 0-32$ & 3 & 5 & 5 & 4 & 25 & 3 & 1 & 3 & 1 & 2 & 2 & 6 & $1 / 0-4$ \\
\hline Stable/slow progression & $\begin{array}{l}42 / 50 \\
84 \%\end{array}$ & $9 / 1850 \%$ & 17/17 100\% & + & + & + & + & + & + & + & - & - & + & + & + & $6 / 1060 \%$ \\
\hline Rapid progression & $8 / 5016 \%$ & $9 / 1850 \%$ & $0 / 160 \%$ & - & - & - & - & - & - & - & + & + & - & - & - & $3 / 1040 \%$ \\
\hline $\begin{array}{l}\text { Preceding autoimmune } \\
\text { diseases }\end{array}$ & $8 / 7611 \%$ & $1 / 274 \%$ & $5 / 2421 \%$ & - & - & + & - & - & - & - & - & - & + & - & - & 0/15 0\% \\
\hline \multicolumn{17}{|l|}{ Clinical features (in \%): } \\
\hline \multicolumn{17}{|l|}{ Weakness: } \\
\hline Neck extensor & $31 / 56(55)$ & $15 / 25(60)$ & $9 / 20(45)$ & - & - & - & + & - & - & + & + & - & - & + & + & $3 / 3(100)$ \\
\hline Neck flexor & $22 / 36(61)$ & $6 / 11(55)$ & $8 / 13(62)$ & - & - & - & - & + & - & + & + & - & - & + & + & $1 / 1(100)$ \\
\hline Abdominal/back & $17 / 25(68)$ & $8 / 10(80)$ & $6 / 9(67)$ & - & - & + & - & - & - & + & + & - & + & + & - & $2 / 2(100)$ \\
\hline Upper limbs & 43/52 (83) & $19 / 19(100)$ & $11 / 17(65)$ & + & - & + & + & - & - & + & + & + & - & + & - & $11 / 11(100)$ \\
\hline Lower limbs & $40 / 49(82)$ & $17 / 18(94)$ & $9 / 15(60)$ & + & + & + & - & + & - & - & + & + & - & + & - & 8/8 (100) \\
\hline Proximal & $59 / 64(92)$ & $27 / 27(100)$ & 18/23 (78) & + & - & + & + & + & - & + & + & + & - & + & - & $15 / 15(100)$ \\
\hline $\begin{array}{l}\text { Predominantly } \\
\text { proximal }\end{array}$ & $43 / 59(73)$ & 25/27 (93) & 14/18 (78) & + & - & + & + & + & - & + & + & + & - & + & - & 14/15 (93) \\
\hline Distal & $31 / 59(53)$ & $11 / 22(50)$ & 10/23 (44) & + & + & - & - & - & - & - & + & - & - & + & - & $4 / 15(27)$ \\
\hline $\begin{array}{l}\text { Predominantly } \\
\text { distal }\end{array}$ & 4/31 (13) & 0/11 (0) & $2 / 10(20)$ & - & + & - & - & - & - & - & - & - & - & - & - & 0/4 (0) \\
\hline Facial weakness & $17 / 48(35)$ & 7/19 (37) & 2/17 (12) & - & - & - & - & - & - & - & - & - & - & - & + & $0 / 4(0)$ \\
\hline Ophthalmoparesis & $1 / 21(5)$ & $0 / 7(0)$ & 1/8 (13) & - & - & - & - & - & - & - & - & - & - & - & + & $0 / 4(0)$ \\
\hline Ptosis & 2/16 (13) & $1 / 6(17)$ & $1 / 8(13)$ & - & - & - & - & - & - & - & - & - & - & - & + & $0 / 4(0)$ \\
\hline Dysphagia & $21 / 45(47)$ & $12 / 22(55)$ & $5 / 16(31)$ & + & - & - & + & - & + & - & - & - & - & - & + & $1 / 5(20)$ \\
\hline Dysarthria & 6/17 (35) & $4 / 8(50)$ & $1 / 7(14)$ & + & - & - & - & - & - & - & - & - & - & - & + & $0 / 0(0)$ \\
\hline Dyspnea & $17 / 31(55)$ & 9/13 (69) & $3 / 7(43)$ & + & - & + & + & - & + & - & - & - & - & - & - & $0 / 1(0)$ \\
\hline Muscle atrophy & 47/53 (89) & 23/24 (96) & 15/18 (83) & + & - & - & + & - & - & + & - & + & + & + & + & $6 / 6(100)$ \\
\hline Myalgia & $20 / 47(43)$ & 5/17 (29) & 5/17 (29) & - & - & + & + & + & + & + & - & - & - & + & - & $4 / 4(100)^{a}$ \\
\hline Cramps & 5/14 (36) & $1 / 4(25)$ & 1/7 (14) & - & - & - & - & - & - & - & - & - & - & + & - & $0 / 0(0)$ \\
\hline Fasciculations & 2/13 (15) & $1 / 6(17)$ & 0/7 (0) & - & - & - & - & - & - & - & - & - & - & - & - & $0 / 0(0)$ \\
\hline \multicolumn{17}{|l|}{ Deep tendon reflexes: } \\
\hline normal & $15 / 38(11)$ & $6 / 12(50)$ & $5 / 13(39)$ & - & - & - & + & + & + & - & + & - & + & - & - & $5 / 8(63)$ \\
\hline increased & 4/38 (39) & $1 / 12(8)$ & 2/13 (15) & - & - & - & - & - & - & - & - & + & - & - & + & $0 / 8(0)$ \\
\hline decreased or absent & 19/38 (50) & $5 / 12(42)$ & 6/13 (46) & + & + & + & - & - & - & + & - & - & - & + & - & 3/8 (38) \\
\hline \multicolumn{17}{|c|}{ Paraclinical examination (in \%): } \\
\hline $\begin{array}{l}\text { IgG gammopathy } \\
\text { present }\end{array}$ & 27/51 (53) & $27 / 27(100)$ & $0 / 24(0)$ & + & - & - & + & NA & - & - & + & + & - & - & - & $3 / 6(50)$ \\
\hline
\end{tabular}


Table 1 Clinical, paraclinical and muscle biopsy features in SLONM, and comparison with HIV-NM (Continued)

\begin{tabular}{|c|c|c|c|c|c|c|c|c|c|c|c|c|c|c|c|c|}
\hline kappa & $14 / 27(52)$ & $14 / 27(52)$ & $0 / 24(0)$ & + & - & - & - & NA & - & - & - & + & - & - & - & $1 / 3(33)$ \\
\hline lambda & $11 / 27(41)$ & $11 / 27(41)$ & $0 / 24(0)$ & - & - & - & + & NA & - & - & + & - & - & - & - & $2 / 3(67)$ \\
\hline kappa + lambda & $1 / 27(4)$ & 1/27 (4) & $0 / 24(0)$ & - & - & - & - & NA & - & - & - & - & - & - & - & 0/3 (0) \\
\hline multiple myeloma & $1 / 27(4)$ & $1 / 27(4)$ & $0 / 20(0)$ & - & - & - & - & NA & - & - & - & - & - & - & - & $0 / 0(0)$ \\
\hline $\begin{array}{l}\text { CK with mean/range } \\
\text { [number of } \\
\text { patients examined] }\end{array}$ & $\begin{array}{l}2.6 / 1- \\
55 \mathrm{~N}[60 / \\
76]\end{array}$ & $\begin{array}{l}1.5 \mathrm{~N} / 1-4 \mathrm{~N} \\
{[24 / 27]}\end{array}$ & $\begin{array}{l}1.9 \mathrm{~N} / 1-17 \mathrm{~N} \\
{[23 / 24]}\end{array}$ & $\mathrm{N}$ & N & $2 \mathrm{~N}$ & $3 N$ & NA & $2 \mathrm{~N}$ & $17 \mathrm{~N}$ & $2 \mathrm{~N}$ & $\mathrm{~N}$ & $\mathrm{~N}$ & $2 \mathrm{~N}$ & $\mathrm{~N}$ & $\begin{array}{l}1.8 \mathrm{~N} / 1- \\
5 \mathrm{~N}[13 / 15]\end{array}$ \\
\hline Respiratory insufficiency & $11 / 20(55)$ & $6 / 9(67)$ & $3 / 8(38)$ & + & NA & - & + & - & + & - & - & - & - & - & - & $0 / 0(0)$ \\
\hline Cardiomyopathy & $3 / 19$ (16) & $1 / 5(20)$ & 2/7 (29) & - & NA & - & dil. & - & dil. & - & - & - & - & - & - & $0 / 0(0)$ \\
\hline \multicolumn{17}{|l|}{ Electromyogram } \\
\hline normal & $2 / 63(3)$ & 0/27 (0) & $2 / 21(10)$ & - & - & - & - & - & - & - & - & - & + & - & - & $0 / 12(0)$ \\
\hline myopathic & $53 / 63(84)$ & 24/27 (89) & 16/21 (76) & - & + & - & + & + & + & + & + & + & - & + & + & $12 / 12(100)$ \\
\hline mixed & 6/63 (10) & $3 / 27(11)$ & $2 / 21(10)$ & + & - & - & - & - & - & - & - & - & - & - & - & $0 / 12(0)$ \\
\hline neurogenic & 2/63 (3) & 0/27 (0) & $1 / 21(5)$ & - & - & + & - & - & - & - & - & - & - & - & - & $0 / 12(0)$ \\
\hline $\begin{array}{l}\text { Genetic panel analysis } \\
\text { performed }\end{array}$ & & & & - & + & - & - & - & + & + & - & - & + & + & + & \\
\hline Muscle biopsy: & & & & $V L$ & TA & $V L$ & D & GM & $\mathrm{D}$ & QF & $\mathrm{VL}$ & QF & $\mathrm{VL}$ & $\mathrm{BF}$ & SC & \\
\hline $\begin{array}{l}\% \text { of rod containing } \\
\text { cells with mean/range } \\
\text { [number of patients } \\
\text { with available data] }\end{array}$ & $\begin{array}{l}28 / 1-63 \\
{[36 / 76]}\end{array}$ & $\begin{array}{l}30 / 3-63[12 / \\
27]\end{array}$ & $\begin{array}{l}22 / 1-50[14 / \\
24]\end{array}$ & 3 & 44 & 3 & 43 & NA & 24 & NA & 16 & 28 & 5 & 14 & 35 & $\begin{array}{l}45 / 35-50 \\
{[3 / 15]}\end{array}$ \\
\hline Intranuclear rods & $4 / 24(17)$ & $2 / 9(22)$ & $0 / 9(0)$ & - & - & - & - & NA & - & - & - & - & - & - & - & $0 / 0(0)$ \\
\hline Muscle fiber atrophy & $\begin{array}{l}45 / 45 \\
(100)\end{array}$ & 15/15 (100) & $13 / 13(100)$ & + & + & + & + & + & + & + & + & + & + & + & + & $14 / 14(100)$ \\
\hline Internalized nuclei & 27/37 (73) & 10/13 (77) & $5 / 11(46)$ & + & + & + & + & + & - & - & + & - & - & - & - & $7 / 7(100)$ \\
\hline $\begin{array}{l}\text { Myofibrillar } \\
\text { disintegration }\end{array}$ & 21/24 (88) & 8/8 (100) & $6 / 9(67)$ & + & + & - & + & NA & + & + & + & + & - & + & - & $2 / 2(100)$ \\
\hline $\begin{array}{l}\text { Lobulated/trabeculated } \\
\text { fibers }\end{array}$ & $17 / 33(52)$ & $7 / 14(50)$ & $9 / 19(50)$ & - & + & - & + & + & - & - & - & - & - & - & + & $1 / 1(100)$ \\
\hline Endomysial fibrosis & $17 / 26(65)$ & $6 / 8(75)$ & 4/9 (44) & + & + & - & + & NA & + & - & + & - & - & - & + & $1 / 1(100)$ \\
\hline Inflammatory infiltrates & 9/53 (17) & $3 / 17(18)$ & $2 / 22(9)$ & - & - & - & - & - & - & - & - & - & - & - & - & $6 / 14(43)$ \\
\hline Necrotic fibers & $\underset{a}{7 / 28(25)}$ & $3 / 10(30)$ & $2 / 12(17)$ & + & - & - & - & NA & + & + & - & - & - & - & - & $4 / 5(80)^{a}$ \\
\hline Core-like areas & $11 / 16(69)$ & $5 / 6(83)$ & $3 / 7(43)$ & + & + & + & - & NA & - & + & + & + & - & - & - & 0/0 (0) \\
\hline Vacuolar changes & $11 / 20(55)$ & $5 / 7(71)$ & $1 / 8(13)$ & + & - & - & + & + & - & + & - & - & - & $+/-$ & - & $5 / 5(100)$ \\
\hline Mitochondrial changes & $11 / 18(61)$ & $2 / 5(40)$ & $3 / 7(17)$ & - & - & unsp. & - & + & - & - & + & - & unsp. & unsp. & - & $1 / 2(50)$ \\
\hline \multicolumn{17}{|c|}{ Therapy (and favorable outcome): } \\
\hline $\begin{array}{l}\text { Immunosuppressive } \\
\text { agents }\end{array}$ & $\begin{array}{l}36 / 58(12 / \\
36)^{a}\end{array}$ & 19/24 (6/19) & $9 / 17(2 / 9)$ & $\begin{array}{l}+ \\
(+)\end{array}$ & - & - & $\begin{array}{l}+ \\
(-)\end{array}$ & - & - & $\begin{array}{l}+ \\
(+)\end{array}$ & $\begin{array}{l}+ \\
(+)\end{array}$ & $\stackrel{+}{(N A)}$ & - & - & - & $8 / 10(8 / 8)^{a}$ \\
\hline $\begin{array}{l}\text { Intravenous } \\
\text { Immunoglobulins }\end{array}$ & $\begin{array}{l}11 / 58(5 / \\
11)\end{array}$ & $7 / 24(3 / 7)$ & $4 / 17(2 / 4)$ & - & - & - & - & - & - & $\begin{array}{l}+ \\
(+)\end{array}$ & - & - & - & - & - & $2 / 10(2 / 2)$ \\
\hline Stem cell therapy & $7 / 58(6 / 7)$ & $7 / 24(6 / 7)$ & $0 / 17(0 / 0)$ & - & - & - & - & - & - & - & $\begin{array}{l}+ \\
(+)\end{array}$ & $\stackrel{+}{(N A)}$ & - & - & - & $0 / 10$ \\
\hline Plasmapheresis & $3 / 58(1 / 3)$ & $2 / 24(0 / 2)$ & $0 / 17(0 / 0)$ & - & - & - & $\begin{array}{l}+ \\
(-)\end{array}$ & - & - & - & - & - & - & - & - & $1 / 10(1 / 1)$ \\
\hline Noninvasive ventilation & $3 / 58$ & $0 / 24$ & $2 / 17$ & + & - & - & - & - & + & - & - & - & - & - & - & $0 / 10$ \\
\hline
\end{tabular}

In bold, statistically significant differences between SLONM with and without monoclonal gammopathy are indicated

HIV-NM HIV-associated nemaline myopathy, $m$ male, $f$ female, y years, + symptom/feature present, $N A$ not available, - symptom/feature not present, IgG immunoglobulin G, CK serum creatine kinase, $N$ normal value (men $<190 \mathrm{U} / \mathrm{l}$, women $<170 \mathrm{U} / \mathrm{I}$ ), dil. dilated cardiomyopathy, VL musculus vastus lateralis, $T A$ musculus tibialis anterior, $D$ musculus deltoideus, $G M$ musculus gluteus medius, $Q F$ musculus quadriceps femoris, $B F$ musculus biceps femoris, $S C$ musculus sternocleidomastoideus, unsp. unspecific mitochondrial changes

${ }^{a}$ indicates statistically significant differences between all SLONM cases and HIV-NM 
Shapiro-Wilk normality tests and compared normally distributed independent samples using Welch's $t$-test, and non-normally distributed independent samples using the Mann-Whitney $U$ test. For categorical variables, the two-tailed Fisher's exact test was applied. Pvalues less than 0.05 were considered to be statistically significant.

\section{Targeted next-generation sequencing (NGS) gene panel}

In 6 SLONM patients without MGUS, targeted NGS was performed using a focused panel of 283 genes (CeGat, Tübingen, Germany). After obtaining written informed consent from each patient, peripheral blood samples were taken and DNA was extracted following standard procedures. The gene panel contained 73 genes that have so far been associated with congenital or distal myopathies, including genes known to cause congenital nemaline myopathy. Of these 73 genes, all variants were further considered. In addition, 210 genes related to diverse myopathies were included, in which only variants that were either marked as "known pathogenic" in the Human Genome Mutation Database $\left(\mathrm{HGMD}^{\circ}\right)$, produced a STOP codon, resulted in a frameshift or were located in an essential splice site, were taken into further consideration. The applied prediction programs were Mutation Taster (MT), PolyPhen-2 (PP-2), PROVEAN, SIFT, Splice-Prediction Program NG2: NetGene2 Server, and Splice-Site Prediction by Neural Network.

\section{Meta-analysis of the literature}

We performed a systematic literature search in PubMed for SLONM cases from 1966 to 2016. All articles written in English, German and French were considered. The same inclusion and exclusion criteria that were used in our study were applied, which resulted in 46 publications comprising 66 SLONM patients in total (Table 1). In order to compare the features of SLONM patients with HIV-associated nemaline myopathy (HIV-NM), we performed an additional literature search for patients with HIV-NM. This resulted in 10 publications comprising 16 cases of HIV-NM (Table 1).

\section{Results}

\section{Clinical and paraclinical features of patients with SLONM} (Table 1)

Our SLONM study cohort comprised 10 new patients and 66 cases culled from the literature (Table 1). Mean age at symptom onset was 52 years, ranging from 25 to 78 years. In half of the patients, first symptoms occurred between 45 and 60 years of age. Sixty percent were diagnosed within the first 2 years after symptom onset, while the longest diagnostic delay was 32 years (Table 1 ).

At disease onset, $80 \%$ of the patients presented with muscle weakness of the proximal lower and/or upper limbs. Neck extensor weakness (dropped head) or dyspnea were the only presenting symptoms in four cases each (8\%). In two patients, isolated dysphagia marked the beginning of the disease (4\%). During the disease course, the predominant clinical phenotype consisted of weakness and atrophy affecting the proximal upper limbs in $84 \%$, proximal lower limbs in $80 \%$, and both proximal upper and lower limbs in $67 \%$ as well as axial weakness (68\%). Dyspnea developed in 55\%, dysphagia in $47 \%$ of the patients. Muscle weakness progressed slowly in most SLONM patients. In one third, there was evidence of facial weakness (35\%) or dysarthria (35\%). Myalgia occurred in $43 \%$, cramps in $36 \%$, and fasciculations in $15 \%$. Other symptoms presented more infrequently: predominantly distal weakness was seen in four patients (13\%), ptosis in two patients (13\%), and ophthalmoparesis was noted in one patient (5\%) (Table 1).

In 53\% of patients with SLONM, an MGUS (IgG) was detected in serum (Table 1). Urine investigations (performed in 5 patients) did not reveal the presence of monoclonal immunoglobulins, except for one case (however, without underlying hematological malignancy) [25]. Fifty-two percent of the MGUS patients had kappa light chains, $41 \%$ lambda, and one patient presented with both kappa and lambda light chains in the serum [26]. An underlying multiple myeloma was found in only one case [27]. Serum CK was mostly normal (72\%) or only slightly increased $(<3 \mathrm{~N} ; 22 \%)$. Three cases presented with hypothyroidism, which could be explained by amiodarone intake in one patient (P4). In the other two, antithyroid peroxidase antibodies and anti-thyroglobulin antibodies were negative in serum. TSH was increased in one [28] and decreased in another [29] patient. Electromyography (EMG) mainly showed myopathic changes (84\%). Ten percent of patients showed a mixed pattern on EMG, two patients presented a purely neurogenic (3\%) ((P3) and [30]) and two more a normal pattern (3\%) ((P9) and [31]). Respiratory insufficiency was detected by spirometry in 55\%. Dilated cardiomyopathy was present in $11 \%$ of patients.

\section{Muscle biopsy findings in patients with SLONM (Table 1)} Nemaline bodies were visible by LM in all except 2 biopsies (P2, P7), in which EM was necessary to detect the rods, which were situated in the sarcoplasm and/or underneath the sarcolemma. Interestingly, intranuclear rods were present in $17 \%$ of the cases, but always combined with intrasarcoplasmic rods. The mean percentage of muscle fibers containing rods was $28 \%$, varying from 1 to $63 \%$ (Table 1). Muscle fiber atrophy was present in all biopsies. Further frequent histopathological findings included myofibrillar disintegration (88\%), core-like areas (69\%), lobulated fibers (52\%) and vacuolar changes 
(55\%). Fiber necrosis was present in $25 \%$ and inflammatory infiltrates were found in $17 \%$ of the biopsies. The infiltrates were restricted to perivascular areas in 2 cases, whereas additional more widespread endomysial infiltrates were observed in the others. Mitochondrial changes (ragged-red fibers, COX-negative fibers and/or paracrystalline inclusions on EM) occurred frequently (64\%). However, these could be explained at least in part as an unspecific age-related phenomenon.

\section{Treatment in patients with SLONM (Tables 1 and 2)}

The most common treatment in SLONM patients was immunosuppressive therapy (62\%), mainly consisting of steroids, with improvement of muscle strength in one third of the patients (Tables 1 and 2). Intravenous immunoglobulins (IVIg) were administered in 19\%; in one third of these cases improvement in muscle strength was achieved. Plasmapheresis was performed in 3 patients, which led to a partial improvement in one of them. The most successful treatment in SLONM patients was highdose melphalan followed by autologous peripheral blood stem cell transplantation (auto-PBSCT), resulting in an improvement in $6 / 7$ treated patients $(86 \%)$. This treatment was performed only in SLONM patients with MGUS. Noninvasive ventilation (NIV) was successful in 4 patients with respiratory insufficiency. Invasive ventilation was performed in one case [6]. All therapeutic regimens and outcomes in all patients for whom this information was available $(n=58)$ are listed in Table 2 .

\section{Comparison between SLONM patients with and without MGUS (Table 1)}

SLONM and MGUS affected significantly more males $(p=0.012)$. Age at onset did not differ significantly between the two groups $(p=0.34)$. SLONM patients with MGUS showed a significantly more rapid disease progression $(p=0.0010)$. Bulbar weakness resulting in dysphagia, dysarthria, and dyspnea was moderately, but not significantly more frequent in patients with MGUS ( $p=$ 0.20-0.36; Table 1). Muscle weakness in upper $(p=$ $0.0064)$ and lower $(p=0.030)$ limbs was significantly more common in patients with MGUS. Although facial $(p=0.13)$, neck extensor $(p=0.38)$, trunk weakness $(p=$ $0.63)$, and respiratory insufficiency $(p=0.35)$ were more commonly present in patients with MGUS, the differences were not statistically significant. Treatment response to immunosuppressive drugs $(p=0.69)$ or IVIg $(p=1.00)$ did not differ significantly between patients with and without MGUS. Plasmapheresis or melphalan followed by auto-PBSCT was only applied in patients with MGUS.

Muscle biopsy of 2 SLONM patients with MGUS revealed intranuclear rods, whereas this feature was not observed in patients without paraproteinemia. Vacuolar changes in muscle fibers were significantly more frequent in SLONM with gammopathy than without ( $p=$ $0.041)$. Myofibrillar disintegration $(p=0.21)$, inflammatory infiltrates $(p=0.64)$, fiber necrosis $(p=0.62)$, and core-like areas $(p=0.27)$ were noted more frequently in SLONM patients with MGUS. However, these differences did not reach significance (Table 1).

\section{Comparison between patients with SLONM and HIV-NM (Table 1)}

There were significantly more males affected by HIVNM compared to the SLONM cohort $(p=0.01)$. Age at onset of HIV-NM cases was significantly lower in comparison to SLONM patients $(p=0.01)$. No significant differences were noted in disease progression $(p=0.37)$ or in any of the clinical features $(p>0.05)$ except for the occurrence of myalgia in patients with HIV-NM ( $p=$ $0.043)$. Facial or respiratory weakness has not yet been reported in patients with HIV-NM. Immunosuppressive therapy (steroids) was administered more frequently in HIV-NM $(p=0.09)$, with a significantly more favorable outcome $(p=0.00071)$. The two muscle biopsy features that significantly distinguished HIV-NM from SLONM were the appearance of inflammatory infiltrates $(p=$ $0.034)$ and fiber necrosis $(p=0.014)$. Interestingly, MGUS was detected in half of the HIV-NM patients, similar to the SLONM cohort.

According to the Classification of the United States Center for Disease Control and Prevention [32], the HIV-status in patients with HIV-NM was heterogeneous (infection stage 1 in five patients; stage 2 in two patients; stage 3 in one patient). The infection stage of the other eight patients remained unknown due to the absence of information in the literature regarding CD4-positive cell count and stage 3-defining opportunistic diseases.

\section{Genetic analyses using a targeted NGS gene panel (Additional file 1: Table S1)}

The variants identified by targeted NGS, after applying a panel of 283 genes, in 6 SLONM patients without MGUS (Table 1) are summarized in Additional file 1: Table S1. We did not identify variants in any of the 11 known genes causing congenital nemaline myopathy (TPM3, NEB, ACTA1, TPM2, TNNT1, KBTBD13, CFN2, KLHL40, KLHL41, LMOD3, MYPN). In two patients (P2, $\mathrm{P} 11)$, a distinct variant of unknown significance was identified in the ryanodine receptor 1 gene (RYR1). Both $R Y R 1$ variants have not been reported before.

There were no common variants among the six SLONM patients in any of the genes tested. The variants identified were heterozygous and for the most part, of unknown significance (Additional file 1: Table S1). In P2 a known mutation was identified in SCN11A that has previously been associated with small-fiber neuropathy 
Table 2 Treatment and outcome in patients with SLONM (novel patients P1-10 and literature data)

\begin{tabular}{|c|c|c|}
\hline Ref. & Treatment & Outcome \\
\hline$P 1^{a}$ & steroids + NIV & $\begin{array}{l}\text { R: improvement of limb and } \\
\text { respiratory strength }\end{array}$ \\
\hline P 2 & NA & NA \\
\hline P 3 & analgetics + physiotherapy & NA \\
\hline \multirow[t]{2}{*}{$P 4^{a}$} & steroids + plasmapheresis & NR, cardiac decompensation \\
\hline & $\begin{array}{l}\text { cyclophosphamide + } \\
\text { rituximab }\end{array}$ & R: stabilisation of weakness \\
\hline P 5 & none & NA \\
\hline P 6 & NIV & NA \\
\hline P 7 & IVlg + steroids & $\begin{array}{l}\text { R: increased muscle strength, CK } \\
\text { remained increased }\end{array}$ \\
\hline$P 8^{a}$ & $\begin{array}{l}\text { auto-PBSCT + melphalan + } \\
\text { dexamethasone }+ \\
\text { lenalidomide }\end{array}$ & R: increased muscle strength \\
\hline$P 9^{a}$ & auto-PBSCT + steroids & NA \\
\hline P 10 & none & NA \\
\hline [24] & none & NA \\
\hline
\end{tabular}

11)

[9] none NA

$(\mathrm{P}$

12)

[54] auto-PBSCT + melphalan

[12] steroids

[12] steroids

[12] steroids

[12] steroids

[12] steroids

[12] steroids

[12] steroids + IVlg + methothrexate

[12] steroids + cyclophosphamide + IVlg

[12] none

NA

[12] none

[12] none

[12] none

[12] none

[12] none

[11] plasmapheresis

steroids + azathioprine

R. paraprotein in serum + rods disappeared, increased muscle strength

NR: died within 1y

NR: died within 1y

NR

NR: stable

NR: died within 1y

NR: stable $14 y$ after onset

NR: stable 6y after onset

NR: stable 4,5y after onset

NA

NA

NA

NA

NA

NR

$R$ : increased muscle strength,
Table 2 Treatment and outcome in patients with SLONM (novel patients P1-10 and literature data) (Continued)

[38] steroids + azathioprine $\quad N R$ myalgia disappeared, serum paraprotein level decreased; weakness relapsed after discontinuation; stable under longterm medication

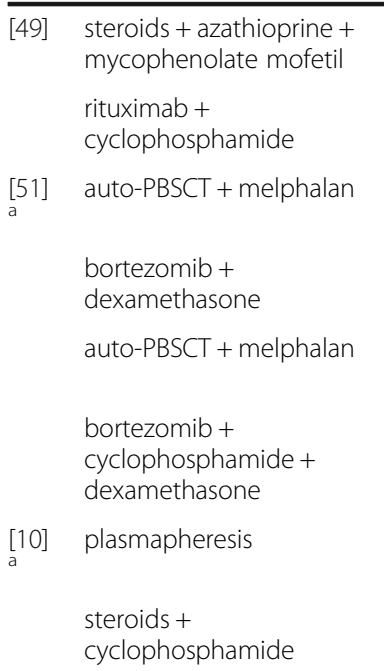

[8] steroids NR

[52] riluzole NR

IVlg NR

[26] steroids + mycophenolate PR: increased muscle strength in mofetil

NR: stable for $2 y$

R: increased muscle strength, followed by stabilization

$\mathrm{R}$ for $4 \mathrm{~m}$, followed by further loss of muscle strength

R: muscle strength improved

R: for 1y, followed by further loss of muscle strength

R: clinical improvement paraprotein in blood disappeared

PR: increased bulbar and neck strength, other muscles NR

PR: increased muscle strength + vital capacity, paraprotein level in blood decreased, patient still disabled

NR

NR legs, neck extensor weakness progressed

IVlg, steroids + mycophenolate mofetil

R: slow modest increase of muscle strength for 6 months

[57] posterior cervical orthodesis R: improved head drop, minimal rotatory restriction

[13] steroids +

cyclophosphamide + IVlg + rituximab

[6] NIV

[31] peridural infiltration

[5] steroids auto-PBSCT + melphalan

NR: died $21 \mathrm{~m}$ after onset

condition stabilized, orthopnea disappeared, weakness remained stable

R: improvement of lumbar

NR

NR

$R$ : increased muscle strength over $1 \mathrm{y}$, further decrease in muscle strength after $2 y$

[25] IVlg

[25] IVlg + steroids + mycophenolate mofetil

$R$ increased muscle strength over $2 y$ with almost complete resolution, stable after $3 y$ therapy

$R$ : increased muscle strength after $1 y$, but significant weakness remained

[27] lenalidomide + dexamethasone

$R$ : significantly increased muscle strength over $3 \mathrm{~m}$, continuing for 4y

[48] auto-PBSCT + melphalan R: increased muscle strength over $1 y$, monoclonal protein level in blood undetectable
[58] IVlg + steroids cruralgia, stable for $3 y$ 
Table 2 Treatment and outcome in patients with SLONM (novel patients P1-10 and literature data) (Continued)

\begin{tabular}{|c|c|c|}
\hline [3] & steroids & NR \\
\hline [21] & steroids + azathioprine & $N R$ \\
\hline [50] & IVlg + steroids & $\mathrm{R}$ : increased muscle strength \\
\hline \multirow{2}{*}[55]{} & steroids & NR \\
\hline & auto-PBSCT + melphalan & $\begin{array}{l}\text { R: increased muscle strength over } \\
15 \mathrm{~m}\end{array}$ \\
\hline [1] & steroids & NR \\
\hline$[1]^{\mathrm{a}}$ & steroids & $N R$ \\
\hline [4] & steroids & NR \\
\hline [59] & steroids + azathioprine & $\begin{array}{l}\text { PR: myalgia disappeared, but } \\
\text { weakness progressed }\end{array}$ \\
\hline [60] & steroids & $\begin{array}{l}\text { R: increased muscle strength, } \\
\text { relapse after discontinuation of } \\
\text { therapy }\end{array}$ \\
\hline [61] & steroids + azathioprine & NR \\
\hline [29] & steroids + IVlg & $\begin{array}{l}\text { NR: skin rash disappeared, } \\
\text { weakness progressed }\end{array}$ \\
\hline $\begin{array}{l}{[62]} \\
\underset{a}{6}\end{array}$ & steroids + IVlg & $N R$ \\
\hline [63] & NIV & R: respiratory weakness resolved \\
\hline
\end{tabular}

$N I V$ noninvasive ventilation, NA not available, $R$ responsive, $P R$ partially responsive, $N R$ not responsive, $I V I g$ intravenous immunoglobulins, $C K$ creatine kinase, auto-PBSCT autologous peripheral blood stem cell therapy, $y$ years, $m$ months

${ }^{a}$ Patients with monoclonal gammopathy

[33]. Our patient did not, however, show any symptoms or signs compatible with small-fiber neuropathy. In P10 a heterozygous variant in SH3TC2 was identified; however, no additional mutation could be found. Homozygous mutations in the SH3TC2 gene cause autosomal recessive Charcot-Marie-Tooth neuropathy [34], heterozygous mutations can cause subtle autosomal dominant distal neuropathy [35]. In the current example, the patient did not show any signs of neuropathy.

\section{Discussion}

The clinical presentation of progressive weakness and atrophy of proximal upper or lower extremity and axial muscles, accompanied by dyspnea and/or dysphagia, represented the predominant clinical phenotype of SLONM. MGUS was a major feature, present in half of the patients, which was not only associated with more rapid disease progression, but also with a favorable response to treatment, especially with melphalan/autoPBSCT.

Neck extensor weakness, sometimes resulting in dropped head, occurred in more than half of the SLONM patients during their disease course. In six cases, dropped head was an initial symptom; accompanied by limb weakness in four, by dysphagia in one patient, and as an isolated finding in another case.
Respiratory affection resulting in dyspnea was present in four patients at disease onset. Interestingly, 3 of these 4 patients with dyspnea as a presenting symptom did not suffer symptoms from insufficient breathing prior to presentation. This lack of respiratory symptoms is considered to be due to the slowness of respiratory decline in SLONM.

Most patients presented with myopathic or mixed EMG patterns. However, one published case [30] and one of our patients (P 3) showed a neurogenic EMG pattern. Neurogenic EMG patterns can appear in severe chronic myopathies (in so-called 'end-stage' muscle) [36, 37]. This could explain at least one of the two cases with a neurogenic EMG [30], as this patient died as the result of her disease one year after presentation. In contrast, the other patient (P 3) did not present a particularly severe chronic myopathy. However, this patient suffered from chronic lower back pains radiating in the legs, which may explain the neurogenic changes on EMG in this patient. An additional peripheral neuropathy was excluded by nerve conduction studies in both patients.

In fact, SLONM should be considered in the differential diagnosis of sporadic inclusion body myositis (sIBM), idiopathic inflammatory myopathies (IIM) and amyotrophic lateral sclerosis (ALS). ALS, similar to SLONM, can present similarly with dropped head, bulbar weakness, dyspnea and fasciculations. There is even more overlap between IIM and SLONM; however, the former usually presents with high serum CK levels, while the latter shows only slight elevations. Inflammatory infiltrates are usually a prominent histopathological feature of IIM, but can also appear in SLONM. However, among the IIMs, polymyositis and sporadic inclusion body myositis (sIBM) are characterized by direct infiltration of muscle fibers by cytotoxic $\mathrm{T}$ lymphocytes immunoreactive for CD8, which was absent in our SLONM cases. Perifascicular muscle fiber atrophy and loss of endomysial capillaries, typically found in dermatomyositis, were also absent in our cases. Sporadic inclusion body myositis may share many clinical similarities with SLONM, including age at onset in late adulthood, weakness of the proximal lower limbs and dysphagia. However, predominantly distal involvement is uncommon in SLONM, in contrast to sIBM. Histopathologically, both sIBM and SLONM present a myopathic pattern, but we could not identify any inclusion bodies (tubulofilamentous inclusions), and only rarely rimmed vacuoles in the SLONM cohort $[38,39]$. Furthermore, in patients with sIBM, nemaline rods do not appear within muscle fibers.

Rarely, SLONM has been reported in combination with thyroid dysfunction. In our study, TSH has been increased in one and decreased in another patient. Since both hyper- and hypothyroidism, as such, may cause myopathy [40], a direct impact of the change in thyroid hormones on muscle might contribute to the disease. 
Several clinical clues, including age at onset, distinguish SLONM from congenital nemaline myopathies. Mean age at onset in the SLONM cohort was 52 years, whereas patients with hereditary nemaline myopathy usually develop symptoms during infancy or early childhood. Furthermore, perinatal hypotonia, delayed motor milestones, scoliosis and a high-arched palate are features of congenital nemaline myopathies and were therefore exclusion criteria for our study. Histopathologically, fiber type 1 predominance, which is typically seen in the congenital forms, was not present in the SLONM cohort. Both congenital and late-onset nemaline myopathies are characterized by the presence of rods in the muscle fibers $[1,41]$. Our genetic analysis did not disclose any mutations in genes known to cause congenital nemaline myopathy. We did not include the very recently reported myopalladin gene $(M Y P N)$ in our gene panel, which in case of mutations was shown to cause nemaline myopathy as well [42]. Thus, mutations in MYPN were not searched for in our SLONM cohort. Furthermore, we did not perform an analysis of copy number variations. In intranuclear rod myopathy, which is a congenital nemaline myopathy with more severe disease course, nemaline rods are frequently found inside myonuclei [43]. Until recently, the only known causative gene was ACTA1 [44]. However, very recently, mutations in the myopalladin gene $(M Y P N)$ were also found to cause intranuclear rods [44], in a relatively mild, childhood- to adult-onset nemaline myopathy with slowly progressive muscle weakness. The publication did not include any patients with SLONM that met our inclusion criteria, as three patients experienced first symptoms in their first decade and the fourth patient showed a positive family history for myopathy with consanguinity and neonatal muscular weakness. Interestingly, the muscle biopsy of two SLONM patients with MGUS and of two SLONM patients lacking immunoelectropheresis revealed intranuclear rods, whereas this feature was not seen in any of our SLONM patients without paraproteinemia. In all four cases with SLONM and intranuclear rods, nemaline bodies were also present in the sarcoplasm [4, 12, 21]. Genetic analysis of ACTA1 was not performed in any of the four cases. The clinical phenotype of patients with SLONM with intranuclear rods was not significantly different compared to other patients with SLONM. In SLONM, nemaline rods are the most striking feature, but other unspecific changes such as fiber atrophy, internalization of nuclei, myofibrillar disintegration were also frequent. Mitochondrial changes, including ragged-red fibers, COX-negative fibers and/or paracrystalline intramitochondrial inclusions detectable by EM, occurred frequently (64\%). These findings might be considered unspecific and age-related in part; however, a more direct effect of Z-disc remodeling on skeletal muscle fiber mitochondria cannot be excluded.

HIV-associated nemaline myopathy showed the same constellation of features seen in SLONM, including proximal limb weakness, myopathic EMG and slightly elevated serum CK levels. However, HIV-NM appears to be more confined to certain muscle groups, since neither facial nor respiratory involvement has been reported to date. Apart from one patient with dysphagia, bulbar weakness has not been described either. Interestingly, the majority of patients $(73 \%)$ showed clinical signs of myopathy before the HIV infection was detected. Therefore, it is important to screen (especially younger) patients with SLONM for HIV infection. Of note, one case has even been described with negative serology at presentation with HIV seropositivity developing only a year after myopathy onset [45]. Histopathologically, there were marginal differences: rods were smaller with $<1 \mu \mathrm{m}$ radius $[15,46]$ and they did not appear inside the nucleus in HIV-NM. Moreover, we observed significantly more frequent myonecrosis and inflammatory infiltrates in HIV-NM. The most compelling difference, however, is the good clinical response of treated HIV-NM cases to immunosuppressive therapy. Combined with muscle involvement during the early stage of HIV infection, this finding might suggest either a direct impact of the viral particles on the formation of rods or an immunological trigger, rather than a degenerative mechanism due to Tcell suppression/immunodeficiency. An HIV-caused genome disturbance has also been discussed as a basis for rod formation [46].

In SLONM with MGUS, not merely the aggregation of paraproteins but rather their effects on autogenous antigens, especially sarcomeric proteins, are thought to cause the formation of rods $[47,48]$. In fact, one case of SLONM with MGUS was described with sarcolemmal deposits of the paraprotein [10], and another suggested immunoreactivity of the sarcolemma to IgG with the paraprotein light chain [11], lending support to this theory. However, a similar immunohistochemical pattern was reported in another publication of a patient without MGUS [28], suggesting a similar pathogenic pathway in SLONM without MGUS. SLONM patients with accompanying autoimmune diseases such as systemic lupus erythematosus (SLE) [49] or Sjögren's syndrome [50] often improved during immunosuppressive medication, whereas the majority of SLONM cases showed a disappointing response rate. This observation might hint at a different nonimmunogenic cause. Another hypothesis suggested that rod formation is part of a regenerative process without the traditional features of muscle repair [29]; however, our findings fail to support this assertion. 
The chronology of the appearance of rods in relation to disease course varied: Nine cases did not show any rods at symptom onset on light microscopy, but only in a subsequent biopsy (P 4) [8, 25, 26, 29, 49, 51-53]. Six cases revealed rods only after severe clinical deterioration (P4) [8, $25,29,51,52]$. Interestingly, this clinical correlation has also been observed the other way around: clinical improvement after auto-PBSCT was accompanied by the disappearance of rods $[54,55]$ as well as paraprotein reduction in SLONM patients with MGUS [56]. Therefore, multiple biopsies during the disease course may be necessary to confirm the diagnosis of SLONM.

Overall, the pathomechanisms of SLONM remain unsolved.

\section{Conclusions}

To conclude, SLONM can be difficult to diagnose in routine clinical practice, not only because of its rarity, but also due to several clinical mimics. However, if an adult patient presents with progressive limb, bulbar and/or respiratory weakness, we recommend respiratory function testing as well as a muscle biopsy that includes a Gomori's trichrome stain in order to identify nemaline rods. If rods are not visible by light microscopy, additional electron microscopic studies are indicated. In addition, all SLONM patients should be screened for a concomitant MGUS or HIV infection, since both have distinct therapeutic and prognostic implications.

\section{Additional file}

Additional file 1: Table S1. Genetic variants identified in patients with SLONM using NGS and a panel of 283 genes. (DOC $72 \mathrm{~kb}$ )

\section{Acknowledgements}

We thank the patients and their families for participating in our study. We are grateful to the technical and administrative personnel of the Department of Neurology and the Institute of Neuropathology at the University Hospital Aachen for their support.

\section{Funding}

This study was funded by a research grant to K.G.C. provided by the Deutsche Gesellschaft für Muskelkranke (DGM) e.V. PVD holds a senior clinical investigatorship of FWO-Vlaanderen.

\section{Availability of data and materials}

The datasets used during the current study are available from the corresponding author on request.

\section{Authors' contributions}

US: Conception and study design, study screening, data extraction and compilation, statistical analysis, interpretation of results, drafting the manuscript. TS, ANP, WS, ER, PVD, AF, SP, CH, AB, AM, JP, TT, DT, JR, PDJ, JJM, PVDB: participation in patient recruitment and data assessment, review and revision of the manuscript. JBS: Overall supervision of the clinical part of the study from conception to completion, review and revision of the manuscript. JW: Overall supervision of the neuropathological part of the study from conception to completion, review and revision of the manuscript. KGC: Conception and study design, interpretation of results, supervising the study, supervising the writing of the manuscript, review and revision of the manuscript. All authors approved the final manuscript.

\section{Competing interests}

DRT received consultancies from Covance Laboratories (UK) and GEHealthcare (UK), received a speaker honorarium from GE-Healthcare (UK) and collaborated with Novartis Pharma Basel (Switzerland).

The authors declare that they have no competing interests.

\section{Consent for publication}

Not applicable.

Ethics approval and consent to participate

The study was approved by the ethical committee of the University Hospital RWTH Aachen (Germany). Written informed consent was obtained from the participating patients.

\section{Publisher's Note}

Springer Nature remains neutral with regard to jurisdictional claims in published maps and institutional affiliations.

\section{Author details}

${ }^{1}$ Department of Neurology, University Hospital RWTH Aachen, Aachen, Germany. ${ }^{2}$ Institute of Neuropathology, University Hospital RWTH Aachen, Aachen, Germany. ${ }^{3}$ Department of Neurology, Medizinisches Zentrum StädteRegion Aachen, Würselen, Germany. ${ }^{4}$ Reference Centre for Neuromuscular Diseases, Department of Neurology, University Hospital Angers, Angers, France. ${ }^{5}$ Department of Neuropathology, Charité Universitätsmedizin Berlin, Berlin, Germany. Institute of Neuropathology, University Hospital Zürich, Zürich, Switzerland. 'Department of Neurology, University Hospitals Leuven, Leuven, Belgium. ${ }^{8}$ Department of Neurosciences, Experimental Neurology, University of Leuven (KU Leuven), Leuven, Belgium. ${ }^{\mathrm{VIB}}$, Center for Brain and Disease Research, Leuven, Belgium. ${ }^{10}$ Department of Neurology, Klinikum Kassel, Kassel, Germany. ${ }^{11}$ Department of Neurology, Hannover Medical School, Hannover, Germany. ${ }^{12}$ Department of Neuropathology, Hannover Medical School, Hannover, Germany. ${ }^{13}$ Institute of Neuropathology, University Hospital Tübingen, Tübingen, Germany. ${ }^{14}$ Department of Neurology, University Hospital Charité Berlin, Berlin, Germany. ${ }^{15}$ Department of Neurology, University Hospital Zurich and University of Zurich, Zurich, Switzerland. ${ }^{16}$ Department of Pathology, University Hospitals Leuven, Leuven, Belgium. ${ }^{17}$ Department of Neurosciences, Experimental Neurology, Laboratory for Neuropathology, University of Leuven (KU Leuven), Leuven, Belgium. ${ }^{18}$ Department of Neurology, University Hospital Bonn, Bonn, Germany. ${ }^{19}$ Department of Neurology, University Hospital Antwerpen, Antwerpen, Belgium. ${ }^{20}$ Institute of Molecular Genetics (VIB), University of Antwerpen, Antwerpen, Belgium.

${ }^{21}$ Born-Bunge Institute, University of Antwerpen, Antwerpen, Belgium.

${ }^{22}$ Department of Neurology, University Hospital Saint-Luc, Brussels, Belgium.

${ }^{23}$ JARA-BRAIN Institute Molecular Neuroscience and Neuroimaging, Forschungszentrum Jülich GmbH and RWTH Aachen University, Aachen, Germany. ${ }^{24}$ Laboratory for Muscle Diseases and Neuropathies, Department of Neurosciences, Experimental Neurology, KU Leuven - University of Leuven, Leuven, Belgium. ${ }^{25}$ Campus Gasthuisberg, Department of Neurology, University Hospitals Leuven and KU Leuven (University of Leuven), Herestraat 49, B-3000 Leuven, Belgium.

Received: 29 December 2016 Accepted: 24 April 2017

Published online: 11 May 2017

\section{References}

1. Engel AG. Late-onset rod myopathy (a new syndrome?): light and electron microscopic observations in two cases. Mayo Clin Proc. 1966;41(11):713-41.

2. Engel WK, Resnick JS. Late-onset rod myopathy: a newly recognized, acquired, and progressive disease. Neurology. 1966;16:308-9.

3. Palmucci L, Doriguzzi C, Mongini T, Chiado-Piat L. Adult onset nemaline myopathy: a distinct nosologic entity? Clin Neuropathol. 1993;12(3):153-5.

4. Engel WK, Oberc MA. Abundant nuclear rods in adult-onset rod disease. J Neuropathol Exp Neurol. 1975:34(2):119-32.

5. Lomen-Hoerth C, Simmons ML, Dearmond SJ, Layzer RB. Adult-onset nemaline myopathy: another cause of dropped head. Muscle Nerve. 1999; 22(8):1146-50

6. Kelly E, Farrell MA, McElvaney NG. Adult-onset nemaline myopathy presenting as respiratory failure. Respir Care. 2008;53(11):1490-4. 
7. Whitaker J, Love S, Williams AP, Plummeridge M. Idiopathic adult-onset nemaline myopathy presenting with isolated respiratory failure. Muscle Nerve. 2009:39(3):406-8.

8. Gyure KA, Prayson RA, Estes ML. Adult-onset nemaline myopathy: a case report and review of the literature. Arch Pathol Lab Med. 1997;121(11):1210-3.

9. Wengert O, Meisel A, Kress W, Dekomien G, Angstwurm K, Heppner FL, Goebel HH, Stenzel W. Progressive external ophthalmoplegia as initial manifestation of sporadic late-onset nemaline myopathy. J Neurol. 2011 ; 258(5):915-7.

10. Eymard B, Brouet JC, Collin H, Chevallay M, Bussel A, Fardeau M. Late-onset rod myopathy associated with monoclonal gammopathy. Neuromuscul Dis. 1993;3(5-6):557-60.

11. Deconinck N, Laterre EC, Van den Bergh PY. Adult-onset nemaline myopathy and monoclonal gammopathy: a case report. Acta Neurol Belg. 2000;100(1):34-40.

12. Chahin N, Selcen D, Engel AG. Sporadic late onset nemaline myopathy. Neurology. 2005;65(8):1158-64.

13. Keller CE, Hays AP, Rowland LP, Moghadaszadeh B, Beggs AH, Bhagat G. Adult-onset nemaline myopathy and monoclonal gammopathy. Arch Neurol. 2006;63(1):132-4.

14. Dalakas MC, Pezeshkpour GH, Flaherty M. Progressive nemaline (rod) myopathy associated with HIV infection. N Engl J Med. 1987;317(25):1602-3.

15. Gonzales MF, Olney RK, So YT, Greco CM, McQuinn BA, Miller RG, DeArmond SJ. Subacute structural myopathy associated with human immunodeficiency virus infection. Arch Neurol. 1988;45(5):585-7.

16. Simpson DM, Bender AN. Human immunodeficiency virus-associated myopathy: analysis of 11 patients. Ann Neurol. 1988;24(1):79-84

17. Dwyer BA, Mayer RF, Lee SC. Progressive nemaline (rod) myopathy as a presentation of human immunodeficiency virus infection. Arch Neurol. 1992:49(5):440

18. Cabello A, Martinez-Martin P, Gutierrez-Rivas E, Madero S. Myopathy with nemaline structures associated with HIV infection. J Neurol. 1990;237(1):64-5.

19. Dubowitz V, Sewry CA, Oldfors A, Lane RJ. Muscle biopsy : a practical approach. 4rthth ed. Oxford: Saunders Elsevier; 2013. p. 2013.

20. Price HM, Gordon GB, Pearson CM, Munsat TL, Blumberg JM. New evidence for excessive accumulation of Z-band material in nemaline myopathy. Proc Natl Acad Sci U S A. 1965;54(5):1398-406.

21. Paulus W, Peiffer J, Becker I, Roggendorf W, Schumm F. Adult-onset rod disease with abundant intranuclear rods. J Neurol. 1988;235(6):343-7.

22. Goebel HH, Warlo I. Nemaline myopathy with intranuclear rods-intranuclear rod myopathy. Neuromuscular Disord. 1997;7(1):13-9.

23. Malfatti E, Romero NB. Nemaline myopathies: State of the art. Rev Neurol. 2016;172(10):614-9.

24. Klarl BA, Bornemann A, Demuth K, Zahringer M, Lindner A. Sporadic adult form of nemaline myopathy-a difficult differential diagnosis. Fortschr Neurol Psychiatr. 2009;77(3):166-8

25. Milone M, Katz A, Amato AA, Soderland CA, Segarceanu M, Young NP Jones HR. Sporadic late onset nemaline myopathy responsive to IVlg and immunotherapy. Muscle Nerve. 2010:41(2):272-6.

26. Irodenko VS, Lee HS, de Armond SJ, Layzer RB. Adult nemaline myopathy with trabecular muscle fibers. Muscle Nerve. 2009:39(6):871-5.

27. Montagnese F, Portaro S, Musumeci O, Migliorato A, Moggio M, Fagiolari G, Rodolico C. Sporadic late-onset nemaline myopathy in a woman with multiple myeloma successfully treated with lenalidomide/dexamethasone. Muscle Nerve. 2015:51(6):934-5.

28. Reyes MG, Tal A, Abrahamson D, Schwartz M. Nemaline myopathy in an adult with primary hypothyroidism. Can J Neurol Sci. 1986;13(2):117-9.

29. Letournel F, Le Clec'h C, Croue A, Marcorelles P, Lavigne C, Penisson-Besnier I. Nemaline bodies as unique pathological feature in the course of treated dermatomyositis. Clin Neuropathol. 2010;29(6):357-60.

30. Brownell AK, Gilbert JJ, Shaw DT, Garcia B, Wenkebach GF, Lam AK. Adult onset nemaline myopathy. Neurology. 1978;28(12):1306-9.

31. Kemta Lekpa F, Chevalier X, Dubourg O, Dimitri D. Isolated camptocormia revealing sporadic late onset nemaline myopathy. Presse medicale (Paris, France : 1983). 2013:42(7-8):1142-4

32. Centers for Disease C, Prevention. Revised surveillance case definition for HIV infection-United States, 2014. MMWR Recomme Rep. 2014;63(Rr-03):1-10.

33. Huang J, Han C, Estacion M, Vasylyev D, Hoeijmakers JG, Gerrits MM, Tyrrell L, Lauria G, Faber CG, Dib-Hajj SD, et al. Gain-of-function mutations in sodium channel $\mathrm{Na}(\mathrm{v}) 1.9$ in painful neuropathy. Brain. 2014;137(Pt 6):1627-42.
34. Lassuthova P, Mazanec R, Vondracek P, Siskova D, Haberlova J, Sabova J, Seeman P. High frequency of SH3TC2 mutations in Czech HMSN I patients. Clin Genet. 2011:80(4):334-45.

35. Lupski JR, Reid JG, Gonzaga-Jauregui C, Rio Deiros D, Chen DC, Nazareth L, Bainbridge M, Dinh H, Jing C, Wheeler DA, et al. Whole-genome sequencing in a patient with Charcot-Marie-Tooth neuropathy. N Engl J Med. 2010;362(13):1181-91.

36. Paganoni S, Amato A. Electrodiagnostic evaluation of myopathies. Phys Med Rehabil Clin N Am. 2013;24(1):193-207.

37. Preston DC, Shapiro BE. Clinical Electrophysiologic Correlations. In: Electromyography and Neuromuscular Disorders. 3 edn. Boston: Mcgill J Med. 2006;9(2):173. 2013:p. 554.

38. Gerard JM, Telerman-Toppet N, Borenstein S, Flament-Durand J. Sporadic Z disk myopathy with accumulation of rods and cytoplasmic bodies. Rev Neurol. 1991:147(2):144-7.

39. Sieb JP, VonOertzen J, Tolksdorf K, Dorfler P, Kappes-Horn K, Jerusalem F. Sporadic adult-onset distal myopathy with rimmed vacuoles, 15-18 nm tubulofilaments and extensive rod formation. J Neurol Sci. 1997;146(1):81-4.

40. Cakir M, Samanci N, Balci N, Balci MK. Musculoskeletal manifestations in patients with thyroid disease. Clin Endocrinol (Oxf). 2003;59(2):162-7.

41. Shy GM, Engel WK, Somers JE, Wanko T. Nemaline myopathy. A new congenital myopathy. Brain. 1963;86:793-810.

42. Miyatake S, Mitsuhashi S, Hayashi YK, Purevjav E, Nishikawa A, Koshimizu E, Suzuki M, Yatabe K, Tanaka Y, Ogata K, et al. Biallelic mutations in MYPN, encoding myopalladin, are associated with childhood-onset, slowly progressive nemaline myopathy. Am J Hum Genet. 2017;100(1):169-78.

43. Goebel HH, Piirsoo A, Warlo I, Schofer O, Kehr S, Gaude M. Infantile intranuclear rod myopathy. J Child Neurol. 1997;12(1):22-30.

44. Schroder JM, Durling H, Laing N. Actin myopathy with nemaline bodies, intranuclear rods, and a heterozygous mutation in ACTA1 (Asp154Asn). Acta Neuropathol. 2004;108(3):250-6.

45. de Sanctis JT, Cumbo-Nacheli G, Dobbie D, Baumgartner D. HIV-associated nemaline rod myopathy: role of intravenous immunoglobulin therapy in two persons with HIV/AIDS. AIDS Read. 2008:18(2):90-4.

46. Feinberg DM, Spiro AJ, Weidenheim KM. Distinct light microscopic changes in human immunodeficiency virus-associated nemaline myopathy. Neurology. 1998;50(2):529-31.

47. Merlini G, Stone MJ. Dangerous small B-cell clones. Blood. 2006;108(8):2520-30.

48. Novy J, Rosselet A, Spertini O, Lobrinus JA, Pabst T, Kuntzer T. Chemotherapy is successful in sporadic late onset nemaline myopathy (SLONM) with monoclonal gammopathy. Muscle Nerve. 2010;41(2):286-7.

49. Dimitri D, Dubourg O. Sporadic late-onset nemaline myopathy in a patient with systemic lupus erythematosus. J Neurol. 2013;260(12):3171-3.

50. Suzuki M, Shimizu Y, Takeuchi M, Kobayashi M, Iwata M, Uchiyama S. Sporadic late-onset nemaline myopathy in a patient with primary Sjogren's syndrome. J Neurol. 2012;259(2):358-60.

51. Doppler K, Knop S, Einsele H, Sommer C, Wessig C. Sporadic late onset nemaline myopathy and immunoglobulin deposition disease. Muscle Nerve. 2013:48(6):983-8.

52. Hanisch F, Schneider I, Muller T, Romeike BF, Stoltenburg G, Holzhausen HJ, Zierz S. Treatability of sporadic late onset nemaline myopathy. Nervenarzt. 2013;84(8):955-61.

53. Kamieniecka Z. Late onset myopathy with rod-like particles. Acta Neurol Scand. 1973;49(4):547-51.

54. Benveniste $\mathrm{O}$, Laforet $\mathrm{P}$, Dubourg $\mathrm{O}$, Solly S, Musset L, Choquet S, Azar N, Fardeau M, Herson S, Leblond V, et al. Stem cell transplantation in a patient with late-onset nemaline myopathy and gammopathy. Neurology. 2008; 71(7):531-2.

55. Voermans NC, Minnema M, Lammens M, Schelhaas HJ, Kooi AV, Lokhorst $H M$, van Engelen BG. Sporadic late-onset nemaline myopathy effectively treated by melphalan and stem cell transplant. Neurology. 2008;71(7):532-4.

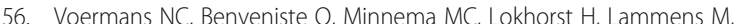
Meersseman W, Delforge M, Kuntzer T, Novy J, Pabst T, et al. Sporadic lateonset nemaline myopathy with MGUS: Iong-term follow-up after melphalan and SCT. Neurology. 2014;83(23):2133-9.

57. Katirji B, Hachwi R, Al-Shekhlee A, Cohen ML, Bohlman HH. Isolated dropped head due to adult-onset nemaline myopathy treated by posterior fusion. Neurology. 2005;65(9):1504-5.

58. Maeda MH, Ohta H, Izutsu K, Shimizu J, Uesaka Y. Sporadic late-onset nemaline myopathy as a rare cause of slowly progressive muscle weakness with young adult onset. Muscle Nerve. 2015;51(5):772-4. 
59. Seitz RJ, Toyka KV, Wechsler W. Adult-onset mixed myopathy with nemaline rods, minicores, and central cores: a muscle disorder mimicking polymyositis. J Neurol. 1984;231(3):103-8.

60. Sun AP, Ohtsuki Y, Yano T, Matsumoto M, Takeuchi T, Furihata M, Arahori M, Sonobe $\mathrm{H}$. Typical nemaline bodies presenting in a patient with polymyositis. Med Electron Microsc. 2002;35(3):167-72.

61. Danon MJ, Giometti CS, Manaligod JR, Perurena OH, Skosey JL. Adult-onset nemaline rods in a patient treated for suspected dermatomyositis. Study with two-dimensional electrophoresis. Arch Neurol. 1981;38(12):761-6.

62. Parks NE, Hanada EY. Maximizing functional independence in sporadic late onset nemaline myopathy. PM \& R. 2012;4(12):1020-3.

63. Falga-Tirado C, Perez-Peman P, Ordi-Ros J, Bofill JM, Balcells E. Adult onset of nemaline myopathy presenting as respiratory insufficiency. Respiration. 1995;62(6):353-4.

Submit your next manuscript to BioMed Central and we will help you at every step:

- We accept pre-submission inquiries

- Our selector tool helps you to find the most relevant journal

- We provide round the clock customer support

- Convenient online submission

- Thorough peer review

- Inclusion in PubMed and all major indexing services

- Maximum visibility for your research

Submit your manuscript at www.biomedcentral.com/submit
Biomed Central 